ИЗВЕСТИЯ АҚАДЕМИИ НАУК ЭСТОНСКОП ССР. ТОМ 25 ХИМИЯ * ГЕОЛОГИЯ. 1976, 수 1

\title{
ИЗМЕНЕНИЕ СОСТАВОВ БИНАРНЫХ ГОМО- И \\ ГЕТЕРОАЗЕОТРОПОВ, ОБРАЗОВАННЫХ $Н$-АЛКЕНАМИ-1 С ВОДОИ И СПИРТАМИ, ПРИ ИЗМЕНЕНИИ ДАВЛЕНИЯ И ТЕМПЕРАТУРЫ
}

Целью настоящей работы является экспериментальное исследование влияния давления и температуры на составы бинарных гомо- и гетероазеотропов, содержащих в качестве одного из компонентов $\boldsymbol{H}$-алкен-1, и проверка надежности полученных экспериментальных данных, необходимых в дальнейшем для обсуждения вопросов, связанных с температурным смещением тройных гетероазеотропов типа вода-спирт-углеводород (производное углеводорода).

\section{Экспериментальная часть} стики:

Вещества, использованные в работе, имели следующие характери-

н-гексен-1

$н$-гептен- 1

H-октен-1

н-гексан

н-гептан

H-октан

этанол

изопропанол

пропанол

изобутанол

бутанол

вода

$n_{D}^{20}$
1,3879
1,4002
1,4087
1,3749
1,3876
1,3976
1,3612
1,3773
1,3854
1,3958
1,3993
1,3333

0,6731

0,6973

0,7150

0,6594

0,6838

0,7025

0,7895

0,7850

0,8035

0,8021

0,8096

1,0000

Чистота веществ проверялась газохроматографически на УХ-1 при максимальной чувствительности самописца, причем примеси обнаружены не были.

Бинарные азеотропы выделялись при помощи ректификации. Колонка имела головку специальной конструкции [ $\left.{ }^{1}\right]$ и была соединена с вакуумной установкой, включающей автоматический маностат, что позволяло проводить ректификацию при любом значении давления в интервале от 200 до 760 мм рт. ст.

Точность определения состава азеотропа при нормальном давлении определяется практически точностью анализа. При пониженных давлениях точность несколько меньше. Можно считать, что температуры кипе- 
ния азеотропов установлены с точностью $0,2^{\circ} \mathrm{C}$, а значения давления пара - с точностью $\pm 2,0$ мм рт. ст. Состав смесей определен газохроматографически на УХ-1. Методика ректификационного выделения гомо- и гетероазеотропов и способ расчета хроматограмм изложены в $\left[{ }^{2,3}\right]$.

Для анализа смесей использовалась колонка длиной $3 \mu$ с наполнителем из $20 \%$ полиэтиленгликоля 4000 на хромосорбе $W$. Температура анализа $70-110^{\circ}$, газ-носитель - гелий, скорость потока газа $50 \mathrm{mл/muн.}$

Таблица 1

Изменение составов бинарных гомо-

и гетероазеотропов при изменении давления и температуры

\begin{tabular}{|c|c|c|c|c|c|c|c|c|}
\hline \multirow{2}{*}{ Бинарный азеотроп } & \multicolumn{2}{|c|}{$\begin{array}{c}P=760 \text { м. } \\
\text { pт. cT. }\end{array}$} & \multicolumn{2}{|c|}{$\begin{array}{c}P=600 \text { м. } \\
\text { рт. ст. }\end{array}$} & \multicolumn{2}{|c|}{$\begin{array}{c}P=400 \text { м. } \\
\text { pт. ст. }\end{array}$} & \multicolumn{2}{|c|}{$\begin{array}{c}P=200 \text { M. } \\
\text { pт. ст. }\end{array}$} \\
\hline & $t_{\mathrm{a} \text { a., }},{ }^{\circ} \mathrm{C}$ & $x_{1}$ & $t_{\text {a } 3 .,}{ }^{\circ} \mathrm{C}$ & $x_{1}$ & $t_{\text {a a., }}{ }^{\circ} \mathrm{C}$ & $x_{1}$ & $t_{\mathrm{a} 3 .},{ }^{\circ} \mathrm{C}$ & $x_{1}$ \\
\hline 1 & 2 & 3 & 4 & 5 & 6 & 7 & 8 & 9 \\
\hline $\begin{array}{l}\text { Гексан (1)—этанол (2) } \\
\text { Гексан (1)- }\end{array}$ & 58,5 & $0,659\left[{ }^{4}\right]$ & 52,3 & $0,669\left[{ }^{4}\right]$ & 41,9 & $0,695\left[{ }^{4}\right]$ & 25,5 & $0,767\left[{ }^{4}\right]$ \\
\hline $\begin{array}{l}\text { Гексан (1)- } \\
\text { изопропанол (2) } \\
\text { Гексан (1)- }\end{array}$ & 62,6 & 0,729 & 55,8 & 0,746 & 45,1 & 0,766 & 29,0 & 0,789 \\
\hline $\begin{array}{l}\text { Гексан (1)- } \\
\text { пропанол(2) } \\
\text { Гептан (1)- }\end{array}$ & 65,3 & $0,845\left[{ }^{4}\right]$ & 58,7 & 0,850 & 47,6 & 0,875 & 30,3 & 0,916 \\
\hline $\begin{array}{l}\text { Гептан (1)- } \\
\text { этанол (2) } \\
\text { Гептан(1)- }\end{array}$ & 72,0 & $0,333\left[{ }^{4}\right]$ & 66,1 & 0,363 & 56,1 & 0,398 & 40,9 & 0,418 \\
\hline $\begin{array}{l}\text { Гептан (1)- } \\
\text { изопропанол (2) } \\
\text { Гептан(1)- }\end{array}$ & 77,1 & 0,374 & 70,7 & 0,394 & 60,5 & 0,430 & 45,1 & 0,471 \\
\hline $\begin{array}{l}\text { пропанол (2) } \\
\text { Октан(1)- }\end{array}$ & 85,1 & 0,538 & 78,0 & 0,557 & 67,3 & 0,603 & 51,6 & 0,637 \\
\hline $\begin{array}{l}\text { изопропанол (2) } \\
\text { Октан (1) - }\end{array}$ & 81,6 & 0,103 & 76,3 & 0,113 & 66,1 & 0,127 & 51,7 & 0,149 \\
\hline $\begin{array}{l}\text { Октан (1)- } \\
\text { пропанол (2) } \\
\text { Октан (1)- }\end{array}$ & 94,1 & 0,253 & 87,0 & 0,285 & 77,7 & 0,313 & 61,7 & 0,352 \\
\hline $\begin{array}{l}\text { Октан (1)- } \\
\text { изобутанол (2) } \\
\text { Октан (1)- }\end{array}$ & 103,3 & 0,324 & 96,1 & 0,352 & 84,5 & 0,382 & 69,0 & 0,444 \\
\hline $\begin{array}{l}\text { бутанол (2) } \\
\text { Гексен-1(1)- }\end{array}$ & 109,4 & 0,446 & 102,2 & 0,481 & 91,2 & 0,516 & 74,1 & 0,582 \\
\hline $\begin{array}{l}\text { пропанол (2) } \\
\text { Гептен-1(1)- }\end{array}$ & 61,7 & $0,902\left[{ }^{1}\right]$ & 55,3 & 0,904 & 43,7 & 0,920 & 26,7 & 0,948 \\
\hline $\begin{array}{l}\text { изопропанол (2) } \\
\text { Гептен-1(1) - }\end{array}$ & 76,0 & 0,420 & 70,2 & 0,432 & 60,2 & 0,453 & 44,9 & 0,478 \\
\hline $\begin{array}{l}\text { пропанол (2) } \\
\text { Октен-1(1) - }\end{array}$ & 83,5 & 0,600 & 76,5 & 0,632 & 65,7 & 0,673 & 49,3 & 0,700 \\
\hline $\begin{array}{l}\text { Октен-1 (1)- } \\
\text { изопропанол (2) } \\
\text { Октен-1(1)- }\end{array}$ & 82,0 & $0,125\left[^{5}\right]$ & 76,1 & 0,141 & 66,3 & 0,163 & 51,8 & 0,196 \\
\hline $\begin{array}{l}\text { Октен-1(1)- } \\
\text { пропанол (2) } \\
\text { Октен-1(1)- }\end{array}$ & 93,7 & 0,286 & 87,4 & 0,311 & 77,3 & 0,326 & 61,7 & 0,378 \\
\hline $\begin{array}{l}\text { Октен-1(1)- } \\
\text { изобутанол (2) } \\
\text { Октен-1(1)- }\end{array}$ & 102,8 & 0,379 & 95,8 & 0,405 & 85,3 & 0,437 & 70,0 & 0,512 \\
\hline 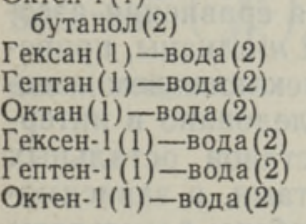 & $\begin{array}{r}108,7 \\
62,3 \\
79,2 \\
89,6 \\
58,4 \\
77,1 \\
88,6\end{array}$ & $\begin{array}{l}0,511\left[{ }^{6}\right] \\
0,788 \\
0,549\left[{ }^{4}\right] \\
0,316[4] \\
0,838[1] \\
0,590[1] \\
0,353[1]\end{array}$ & $\begin{array}{r}101,0 \\
55,8 \\
72,9 \\
82,7 \\
51,9 \\
70,3 \\
81,8\end{array}$ & $\begin{array}{l}0,542 \\
0,802 \\
0,559 \\
0,328 \\
0,850 \\
0,603 \\
0,363\end{array}$ & $\begin{array}{l}90,3 \\
44,6 \\
63,2 \\
72,9 \\
41,4 \\
61,0 \\
72,1\end{array}$ & $\begin{array}{l}0,574 \\
0,825 \\
0,578 \\
0,336 \\
0,858 \\
0,622 \\
0,370\end{array}$ & $\begin{array}{l}72,0 \\
28,4 \\
47,1 \\
57,1 \\
24,8 \\
45,4 \\
56,1\end{array}$ & $\begin{array}{l}0,635 \\
0,858 \\
0,611 \\
0,347 \\
0,887 \\
0,662 \\
0,389\end{array}$ \\
\hline
\end{tabular}

Результаты экспериментального определения температур кипения и составов бинарных гомо- и гетероазеотропов в интервале давлений $200-$ 760 мм рт. ст. приведены в табл. 1. 


\section{Обсуждение результатов}

Для оценки надежности полученных данных о составах и температуpax кипения гетероазеотропов, образованных компонентами с ограниченной взаимной растворимостью, пользовались критерием надежности, приведенным в [7].
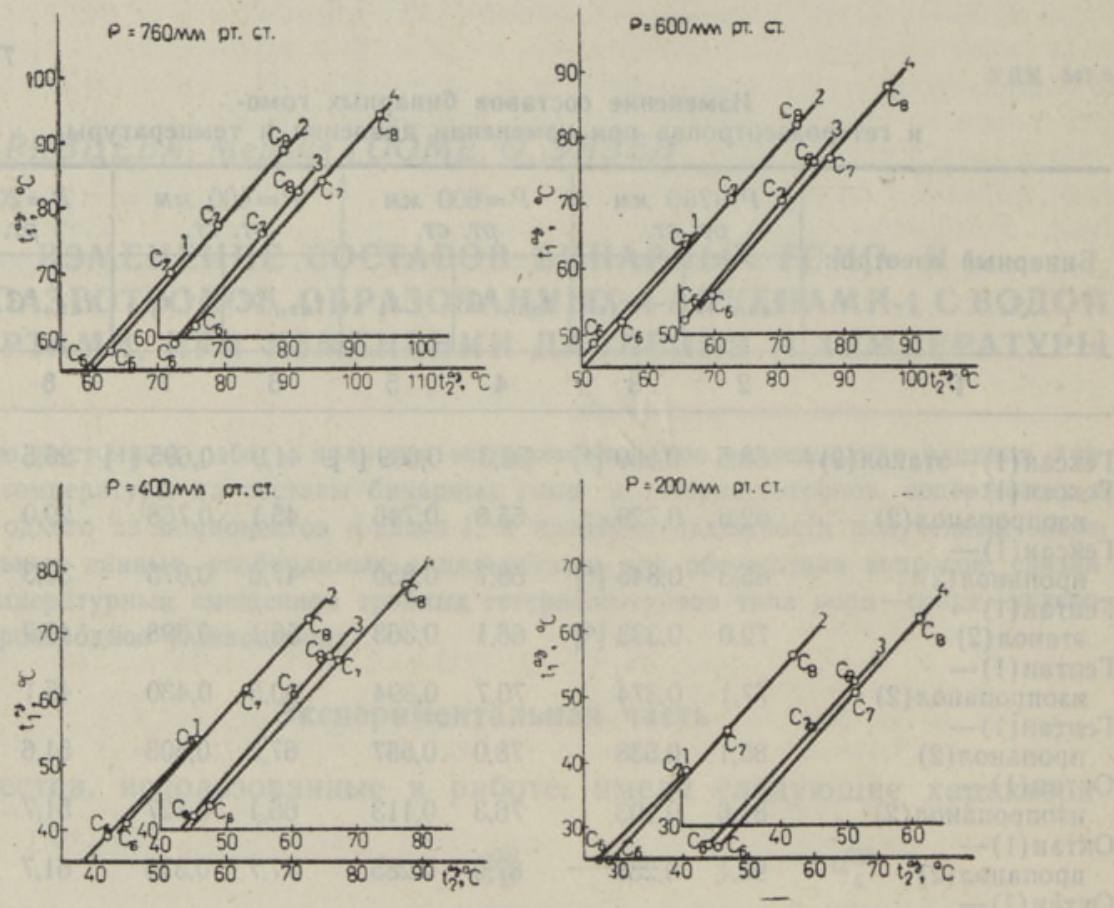

Рис. 1. Взаимосвязь между температурами кипения азеотропов, образованных $\boldsymbol{H}$-алкенами-1 и $\boldsymbol{H}$-алканами с водой и спиртами.

Индекс 1 относится к $\boldsymbol{H}$-алкену-1, 2 - к $\boldsymbol{н}$-алкану.

Азеотропы, содержащие этанол (1), воду (2), изопропанол (3) и пропанол (4).

Для проверки согласованности данных о температурах кипения гомоазеотропов использовался метод сравнения [8]. Полученные ранее [6, 9] и в настоящей работе данные о составах и температурах кипения бинарных азеотропов $\boldsymbol{H}$-алкен-1-спирт и $\boldsymbol{H}$-алкен-1-вода были графически сопоставлены с азеотропными свойствами систем, содержащих вместо алкена-1 $н$-алкан с тем же числом атомов углерода в молекуле. Результаты сравнения изображены на рис. 1 и 2 . Необходимые для сравнения азеотропные характеристики бинарных систем, содержащих $н$-алканы, приведены в литературе [4] для нормального давления, за исключением азеотропа гексан-этанол, изменение состава которого исследовано в интервале давлений 200-760 мм рт. ст. [ $\left.{ }^{4}\right]$. Изменение составов остальных азеотропов, образованных $\boldsymbol{H}$-алканами с водой и спиртами, в зависимости от изменения давления исследовано в настоящей работе; результаты приведены в табл. 1.

Данные о зависимости температур кипения бинарных азеотропов от давления коррелировались с помощью уравнения Антуана, константы которого приведены в табл. 2. 


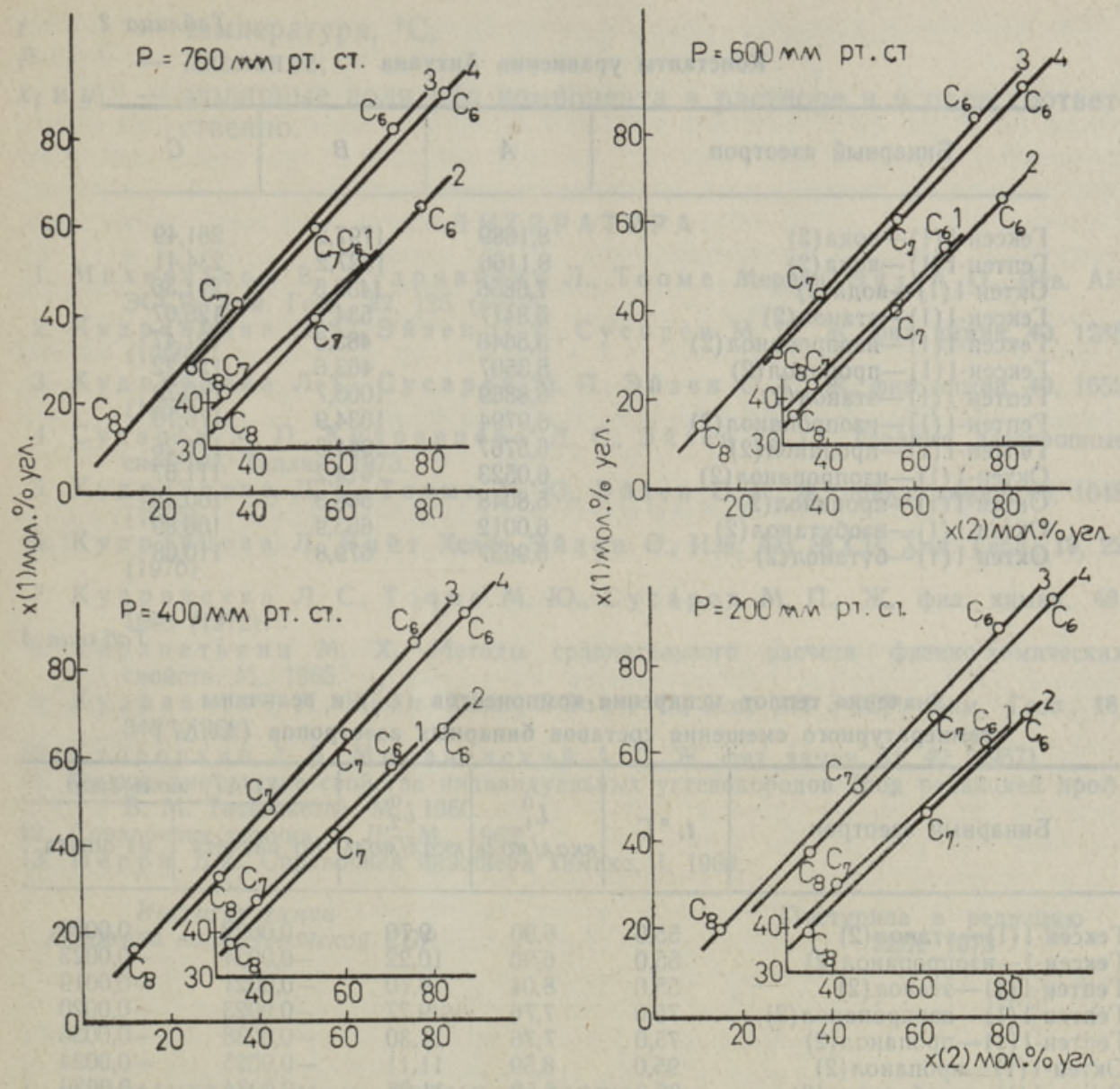

Рис. 2. Взаимосвязь между составами азеотропов, образованных $\mu$-алкенами-1 и $\boldsymbol{H}$-алканами с водой и спиртами.

Обозначения см. рис. 1 .

Смещение составов азеотропов с изменением температуры было определено по уравнению $\left[{ }^{10}\right]$

$$
\left(\frac{d x}{d T}\right)_{\text {aа. }}=\frac{x_{1} \cdot x_{2}}{1-\left(\frac{\partial y_{1}}{\partial x_{1}}\right)_{T, P}^{\text {a3. }}} \cdot \frac{L_{1}-L_{2}}{R T^{2}}
$$

Величина $\left(\frac{\partial y_{1}}{\partial x_{1}}\right)_{T, P}^{\text {аз. }}$ для гомоазеотропов рассчитана по данным о равновесии жидкость-пар, приведенным в [6, 9]. Для гетероазеотропов

$$
\left(\frac{\partial y_{1}}{\partial x_{1}}\right)_{T, P}^{\text {aa. }}=0
$$

Из-за отсутствия данных о парциальных молярных теплотах испарения при расчете мы пользовались значениями теплот испарения чистых компонентов, полученными для $H$-алкенов-1 и воды интерполяцией на необходи . мую температуру результатов, приведенных в $\left[{ }^{11}\right]$ и $\left[{ }^{12}\right]$ соответственно. 
Константы уравнения Антуана

\begin{tabular}{|c|c|c|c|}
\hline Бинарный азеотроп & $A$ & $B$ & C \\
\hline 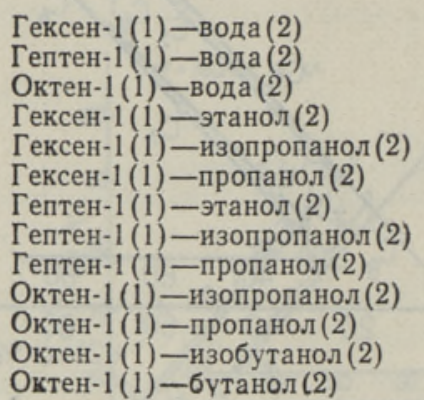 & $\begin{array}{l}8,1689 \\
8,1166 \\
7,6856 \\
5,8417 \\
5,5648 \\
5,3507 \\
6,8869 \\
6,9794 \\
6,5767 \\
6,0523 \\
5,8048 \\
6,0012 \\
5,9937\end{array}$ & $\begin{array}{r}1797,2 \\
1627,2 \\
1439,5 \\
534,1 \\
483,6 \\
463,6 \\
1003,7 \\
1034,9 \\
941,3 \\
614,2 \\
568,3 \\
653,9 \\
679,8\end{array}$ & $\begin{array}{l}281,49 \\
234,41 \\
211,36 \\
125,67 \\
121,47 \\
125,22 \\
180,70 \\
176,16 \\
171,26 \\
111,67 \\
100,48 \\
106,89 \\
110,08\end{array}$ \\
\hline
\end{tabular}

Таблица 3

Значения теплот испарения компонентов $\left(L_{1}^{0}\right)$ и величины температурного смещения составов бинарных азеотропов $(\Delta x / \Delta T)$

\begin{tabular}{|c|c|c|c|c|c|}
\hline \multirow[b]{2}{*}{ Бннарный азеотроп } & \multirow[b]{2}{*}{$t,{ }^{\circ} \mathrm{C}$} & \multirow{2}{*}{$\begin{array}{c}L_{1,}^{0} \\
\kappa \kappa a \Omega / \text { моль }\end{array}$} & \multirow{2}{*}{$\begin{array}{c}L_{2}^{0} \\
\kappa \kappa a \Omega / \text { моль }\end{array}$} & \multicolumn{2}{|c|}{$\Delta x / \Delta T$, моль/град } \\
\hline & & & & по расчету & из опыта \\
\hline 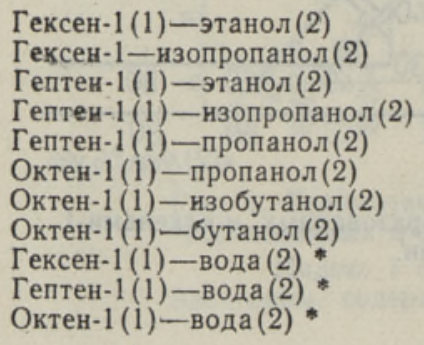 & $\begin{array}{l}55,0 \\
55,0 \\
55,0 \\
75,0 \\
75,0 \\
95,0 \\
95,0 \\
95,0 \\
51,9 \\
70,3 \\
81,8\end{array}$ & $\begin{array}{l}6,90 \\
6,90 \\
8,04 \\
7,76 \\
7,76 \\
8,59 \\
8,59 \\
8,59 \\
6,95 \\
7,83 \\
8,78\end{array}$ & $\begin{array}{r}9,70 \\
10,22 \\
9,70 \\
9,77 \\
11,30 \\
11,11 \\
11,23 \\
11,61 \\
10,22 \\
10,02 \\
9,90\end{array}$ & $\begin{array}{l}-0,0029 \\
-0,0024 \\
-0,0021 \\
-0,0023 \\
-0,0038 \\
-0,0025 \\
-0,0034 \\
-0,0038 \\
-0,0020 \\
-0,0023 \\
-0,0011\end{array}$ & $\begin{array}{l}-0,0029 \\
-0,0023 \\
-0,0019 \\
-0,0020 \\
-0,0036 \\
-0,0024 \\
-0,0030 \\
-0,0037 \\
-0,0021 \\
-0.0023 \\
-0,0011\end{array}$ \\
\hline
\end{tabular}

* При расчете $\Delta x / \Delta T$ использовались данные для давления 760 мм рт. ст. Минус означает, что с понижением температуры содержание спирта и воды в азеотропах уменьшается.

Для спиртов пересчет значений $L_{i}{ }^{0}$ на необходимую температуру проводился по формуле Ватсона [13].

Величины относительного смещения состава азеотропа $\Delta x / \Delta T$, определенные по экспериментальным данным, приведены в табл. 3 .

Максимальное расхождение результатов расчета состава гомоазеотропа с экспериментальными данными $\pm 1,5$ мол. \%, состава гетероазеотропа $\pm 0,5$ мол. $\%$.

\section{Обозначения}

$\begin{array}{ll}L_{i} & \text { - парциально-молярная теплота испарения } i \text {-го компонента; } \\ L_{i}^{0} & \text { - молярная теплота испарения } i \text {-го компонента; } \\ R & \text { - универсальная газовая постоянная; } \\ T & \text { - температура, K; }\end{array}$ 


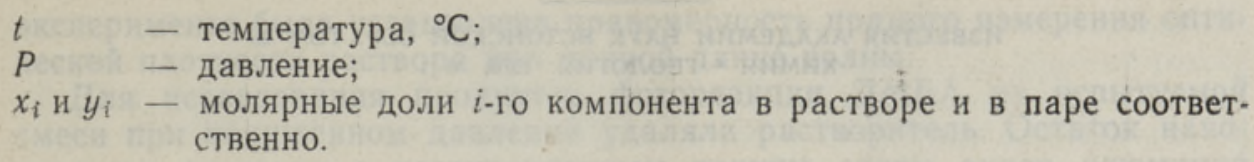

\section{Л ИТ Е Р А У Р А}

1. Михкельсон В., Кудрявцева Л., Тооме Мерике, Эйзен О., Изв. АН ЭССР, Хим. Геол., 22, 125 (1973).

2. Куд ря вцев а Л. С., Э й зен О. Г., С ус а рев М. П., Ж. фнз. хнмин, 40, 1285 (1966).

3. Қуд р я вце в а Л. С., С ус а ре в М. П., Э й зе н О. Г., Ж. физ. химии, 40, 1652 (1966).

4. Сусарев М. П., Кудрявцев а Л. С., Эйзен О.Г., Тройные азеотропные системы, Таллин, 1973.

5. К уд ря вце в а Л, С., Т о ом е М. Ю., Эй зен О. Г., Ж. прикл. химии, 48, 1048 (1975).

6. Куд р я в ц в а Л., В и й т Хелле, Эй зен О., Изв. АН ЭССР, Хим. Геол., 19, 22 (1970),

7. Кудрявдева Л. С., Тооме М. Ю., Сусарев М. П., Ж. физ. химни, 46, 1698 (1972).

8. К а рапетьянц $\mathrm{M}$. Х., Методы сравнительного расчета физико-химических свойств, М., 1965.

9. Куд рявцева Л., Вийт Хелле, Эйзен О., Извь АН ЭССР, Хим. Геол., 18, 346 (1969).

10. С торонкин А. В., Мор а чев ский А. Г., Ж. физ. химии, 31,42 (1957).

11. Физико-химические свойства индивидуальных углеводородов (под редакцией проф. В. М. Татевского), М., 1960.

12. Справочник химика, I, Л.-М., 1962

13. Перр и Дж., Справочник инженера химика, I, 1969.

Институт химии

Академии наук Эстонской ССР

\section{Поступила в редакцию} $22 / \mathrm{X} 1973$

\section{KUDRJAVTSEVA, Merike TOOME, O. EISEN}

\section{HOMO- JA HETEROASEOTROOPSETE SEGUDE $n$-ALKEEN-1-VESI JA n-ALKEEN-1-ALKOHOL KOOSTISE SOLTUVUS TEMPERATUURIST JA ROHUST}

Määrati homo- ja heteroaseotroopsete segude $n$-alkeen-1-vesi ja $n$-alkeen-1alkohol koostise sōltuvus temperatuurist ja rõhust vahemikus $200-760 \mathrm{~mm} \mathrm{Hg}$. Tulemusi võrreldi binaarsete homo- ja heteroaseotroopsete segudega, mis moodustuvad $n$-alkaanide ja vee ning $n$-alkaanide ja alkoholide vahel. Katseandmed esitatakse analüütiliste seoste abil.

\section{KUDRJAWZEWA, Merike TOOME, O. EISEN}

\section{DIE DRUCK- UND TEMPERATURVERÄNDERLICHKEIT DER ZUSAMMENSETZUNG DER BINÄREN AZEOTROPE, WELCHE VON DEN ALKENEN MIT ALKOHOLEN UND WASSER GEBILDET WERDEN}

Es wurde die Druck- und Temperaturveränderlichkeit der Zusammensetzung obengenannter Homo- und Heteroazeotropen unter Verwendung der Destillationskolonne im Druckintervall 200-760 Torr untersucht. Die Ergebnisse wurden mit den von Alkanen gebildeten Azeotropen verglichen und in analytischen Beziehungen ausgedrückt. 